\title{
Carbohydrate composition of circulating multiple-modified low-density lipoprotein
}

This article was published in the following Dove Press journal:

Vascular Health and Risk Management

14 October 2016

Number of times this article has been viewed

\author{
Emile R Zakiev' \\ Igor A Sobenin ${ }^{1,2}$ \\ Vasily N Sukhorukov' \\ Veronika A Myasoedova' \\ Ekaterina A Ivanova ${ }^{3}$ \\ Alexander N Orekhov ${ }^{1,4}$ \\ 'Laboratory of Angiopathology, \\ Institute for General Pathology and \\ Pathophysiology, 'Laboratory of \\ Medical Genetics, Russian Cardiology \\ Research and Production Complex, \\ Moscow, Russia; ${ }^{3}$ Department of \\ Development and Regeneration, KU \\ Leuven, Leuven, Belgium; ${ }^{4}$ Skolkovo \\ Innovative Center, Institute for \\ Atherosclerosis Research, Moscow, \\ Russia
}

\begin{abstract}
Atherogenic modification of low-density lipoprotein (LDL) plays a crucial role in the pathogenesis of atherosclerosis, as modified LDL, but not native LDL, induces pronounced accumulation of cholesterol and lipids in the arterial wall. It is likely that LDL particles undergo multiple modifications in human plasma: desialylation, changes in size and density, acquisition of negative electric charge, oxidation, and complex formation. In a total LDL preparation isolated from pooled plasma of patients with coronary atherosclerosis and from healthy subjects, two subfractions of LDL could be identified: desialylated LDL bound by a lectin affinity column and normally sialylated (native) LDL that passed through the column. The desialylated LDL subfraction therefore represents circulating modified LDL. In this work, we performed a careful analysis of LDL particles to reveal changes in the composition of glycoconjugates associated with proteins and lipids. Protein fraction of LDL from atherosclerotic patients contained similar amounts of glucosamine, galactose, and mannose, but a 1.6-fold lower level of sialic acid as compared to healthy donors. Lipid-bound glycoconjugates of total LDL from patients with coronary atherosclerosis contained 1.5-2-fold less neutral monosaccharides than total LDL from healthy donors. Patient-derived LDL also contained significantly less sialic acid. Our results demonstrate that carbohydrate composition of LDL from atherosclerotic patients was altered in comparison to healthy controls. In particular, prominent decrease in the sialic acid content was observed. This strengthens the hypothesis of multiple modification of LDL particles in the bloodstream and underscores the clinical importance of desialylated LDL as a possible marker of atherosclerosis progression.
\end{abstract}

Keywords: atherosclerosis, low density lipoprotein, LDL, modified LDL, desialylation

\section{Introduction}

Atherosclerosis is triggered by lipid accumulation in subendothelial arterial cells. ${ }^{1}$ Intracellular lipid accumulation is caused by low-density lipoprotein (LDL) circulating in human blood. However, only modified lipoprotein, but not native LDL, causes intracellular lipid accumulation. ${ }^{2}$ Although oxidation remains the most studied form of atherogenic modification, other modifications of LDL can also be detected in the bloodstream. A study of the total LDL from the blood of atherosclerosis patients revealed the presence of desialylated LDL particles with atherogenic properties. ${ }^{2}$ Glycosphingolipids in LDL usually have a terminal sialic acid residue. In case of removal of this terminal sialic acid, modified glycosphingolipid will have galactose as the terminal saccharide residue. We took advantage of this fact to isolate the subfraction of desialylated LDL from total LDL preparation using Ricinus communis agglutinin (RCA120), which possesses a high affinity to the terminal galactose. ${ }^{2}$ Total LDL preparation was applied on column with RCA120 immobilized on
Correspondence: Ekaterina A Ivanova Department of Development and Regeneration, KU Leuven, 3000 Leuven, Herestraat 49, O\&N3, Belgium Tel +32488461692

Email kate.ivanov@gmail.com

Alexander N Orekhov Laboratory of Angiopathology, Institute for General Pathology and Pathophysiology, I25315 Moscow, Russia Email a.h.opexob@gmail.com 
CNBr-activated agarose. Normally, sialylated LDL passed through the column not binding to the sorbent. Desialylated LDL was bound to lectin and then eluted with 5-50 mM galactose. This method allowed us to isolate subfractions of both sialylated and desialylated LDL from total LDL preparation isolated from the blood of patients. We called the latter subfraction as circulating modified LDL (cmLDL). In this study, we focus on chemical analysis of LDL particles including studying the carbohydrate composition of apoBand lipid-bound glycoconjugates of native and modified LDL obtained from healthy donors and atherosclerotic patients.

\section{Materials and methods}

\section{Study subjects}

This study was conducted in accordance with the Declaration of Helsinki as revised in 1983. It was approved by the local ethics committees of the Institute of General Pathology and Pathophysiology (Moscow) and Institute for Atherosclerosis Research (Skolkovo Innovation Center, Moscow, Russia). All participants provided their written informed consent prior to their inclusion in the study. Study subjects included men and women aged 30-60 years with angiographically proven coronary atherosclerosis, healthy subjects aged 25-55 years with no signs of ischemic heart disease according to Rose questionnaire, ${ }^{3,4}$ and individuals with asymptomatic carotid atherosclerosis. The characteristics of patients are presented in Table 1. The following are the inclusion and exclusion criteria by the study protocol. Men and women aged 22-55 years without clinical manifestations of cardiovascular atherosclerosis-related diseases, in whom high-resolution B-mode ultrasonography has revealed no signs of subclinical atherosclerosis (normal values of carotid intima-media thick- ness and the absence of atherosclerotic plaques in carotids), were eligible for inclusion in the study as "healthy subjects". Men and women aged 22-55 years without clinical manifestations of cardiovascular atherosclerosis-related diseases but with ultrasonographic signs of subclinical atherosclerosis (abnormally high values of carotid intima-media thickness and the presence of atherosclerotic plaques in carotids with $>10 \%$ stenosis) were eligible for inclusion in the study as "individuals with asymptomatic carotid atherosclerosis". Finally, patients with coronary heart disease aged 30-60 years with coronary atherosclerosis proven by coronary angiography were eligible for inclusion in the study as "patients with coronary atherosclerosis", regardless of the presence and extent of carotid atherosclerosis. For all study participants, the presence of arterial hypertension (systolic blood pressure $>140 \mathrm{mmHg}$, diastolic blood pressure $>90 \mathrm{mmHg}$ ) or type 2 diabetes mellitus, or intake of lipid-lowering agents at least within 2 months prior to inclusion, was evaluated as exclusion criteria.

\section{Preparation of blood plasma}

Venous blood was collected from healthy subjects, patients with angiographically documented coronary atherosclerosis, and patients with subclinical carotid atherosclerosis into tubes containing EDTA ( $1 \mathrm{mg} / \mathrm{mL})$ after overnight fasting. Plasma was separated by centrifugation (20 minutes at $900 \mathrm{~g}$ ).

\section{Total LDL preparation}

Total LDL fraction was isolated from blood plasma as described previously. ${ }^{5}$ For LDL isolation, plasma density was adjusted to $1.390 \mathrm{~g} / \mathrm{mL}$ with solid $\mathrm{NaBr}$, and $4 \mathrm{~mL}$ of plasma was transferred into polycarbonate centrifuge bottles $(16 \times 76 \mathrm{~mm}$, Beckman Instruments, Inc., Palo Alto,

Table I Characteristics of patients

\begin{tabular}{|c|c|c|c|}
\hline Variable & Healthy subjects & $\begin{array}{l}\text { Patients with subclinical } \\
\text { carotid atherosclerosis }\end{array}$ & $\begin{array}{l}\text { Patients with coronary } \\
\text { atherosclerosis }\end{array}$ \\
\hline Age, years & $46.6 \pm 10.9$ & $49.2 \pm 9.8$ & $58.5 \pm 8.6^{a}$ \\
\hline Body mass index, $\mathrm{kg} / \mathrm{m}^{2}$ & $26.1 \pm 3.7$ & $26.7 \pm 3.7$ & $27.0 \pm 3.8$ \\
\hline Systolic blood pressure, $\mathrm{mmHg}$ & $140 \pm 15$ & $143 \pm 18$ & $143 \pm 18$ \\
\hline Diastolic blood pressure, $\mathrm{mmHg}$ & $85 \pm 10$ & $86 \pm 11$ & $80 \pm 12$ \\
\hline Smoking, \% & 12 & 15 & 12 \\
\hline Family history of CHD, \% & 24 & 20 & 26 \\
\hline Family history of hypertension, $\%$ & 36 & 36 & 43 \\
\hline Family history of type 2 diabetes, $\%$ & II & 10 & 10 \\
\hline Total cholesterol, mg/dL & $183 \pm 46$ & $186 \pm 44$ & $18 \mid \pm 38$ \\
\hline Triglycerides, mg/dL & $130 \pm 79$ & $135 \pm 75$ & $126 \pm 62$ \\
\hline HDL cholesterol, mg/dL & $55 \pm 16$ & $55 \pm 13$ & $54 \pm 15$ \\
\hline LDL cholesterol, mg/dL & $104 \pm 40$ & $109 \pm 39$ & $107 \pm 39$ \\
\hline
\end{tabular}

Notes: Ten subjects were involved in each group. Data are presented as mean \pm SD. ${ }^{\text {a }}$ Statistically significant difference from healthy subjects, $P<0.05$.

Abbreviations: CHD, coronary heart disease; HDL, high-density lipoprotein; LDL, low-density lipoprotein; SD, standard deviation. 
CA, USA). Six milliliters of $\mathrm{NaBr}$ solution $(d=1.019 \mathrm{~g} / \mathrm{mL})$ was layered over the plasma and centrifuged for 2 hours at $116763 \mathrm{~g} \mathrm{(42000} \mathrm{rpm)} \mathrm{in} \mathrm{a} \mathrm{Type} \mathrm{50Ti} \mathrm{rotor} \mathrm{(Beckman}$ Instruments). The lower layer of LDL (1.5 $\mathrm{cm}$ over the plasma level) was aspirated, and the density was adjusted to $1.470 \mathrm{~g} / \mathrm{mL}$ with solid $\mathrm{NaBr}$. The samples were recentrifuged under the same conditions and dialyzed in the dark at $4^{\circ} \mathrm{C}$ overnight against 2,000 volumes of phosphate-buffered saline, $\mathrm{pH} 7.4$, containing $1 \mathrm{mM}$ EDTA. LDL preparations were sterilized by filtration (pore size, $0.45 \mu \mathrm{m}$ ) and stored at $4^{\circ} \mathrm{C}$ for $1-5$ days prior to carbohydrate measurement. The LDL preparations obtained by this technique were free from other plasma proteins and were identical in particle size and lipid composition to LDL isolated by the classical method.

\section{Lectin chromatography of modified LDL}

Apolipoprotein B (apoB), the only protein found in LDL, contains two types of oligosaccharide conjugates, oligomannoside and terminally sialylated. ${ }^{6,7}$ Glycosphingolipids in LDL also have a terminal sialic acid residue. ${ }^{8}$ Desialylation will result in the exposure of the next residue of the carbohydrate chain, which is galactose. Correspondingly, we hypothesized that desialylated LDL will interact with galactose-specific lectins, such as Ricinus communis agglutinin (RCA120). ${ }^{9}$ To prepare the affinity columns, RCA120 was immobilized on $\mathrm{BrCN}$-activated agarose as described earlier. ${ }^{10}$ The columns were equilibrated with $10-15 \mathrm{~mL}$ of isotonic phosphate buffer, $\mathrm{pH} 7.2$, and $0.5-5 \mathrm{~mL}$ of LDL sample (containing $0.2-10 \mathrm{mg}$ of protein) was loaded on the column. The major part of unbound LDL was washed from the column in the first ten volumes of phosphate buffer. Desialylated LDL was washed from the column with galactose solutions in phosphate buffer (5 mM, $10 \mathrm{mM}, 20 \mathrm{mM}, 50 \mathrm{mM}$, and $100 \mathrm{mM})$. Washing with $50 \mathrm{mM}$ galactose resulted in virtually complete elution of LDL in the first five volumes and this concentration was used most often. ${ }^{11}$ Bound and unbound LDL fractions were brought to the density of $1.070 \mathrm{~g} / \mathrm{mL}$ with $\mathrm{NaBr}$, concentrated by ultracentrifugation, and dialyzed against 6,000 volumes of isotonic phosphate buffer as described earlier.

\section{Carbohydrate and sialic acid analysis}

Fluorescently labeled N-glycans are separated by hydrophilic liquid chromatography on a Waters Acquity ultraperformance liquid chromatography instrument (Waters, Milford, MA, USA) consisting of a quaternary solvent manager, sample manager, and an FLR fluorescence detector set with excitation and emission wavelengths of $250 \mathrm{~nm}$ and $428 \mathrm{~nm}$, respectively. The instrument is under the control of Empower 3 software, build 3471 (Waters). Labeled plasma N-glycans are separated on a Waters Ethylene Bridged Hybrid Glycan chromatography column, $150 \times 2.1 \mathrm{~mm}$ Internal Diameter, $1.7 \mu \mathrm{m}$ Ethylene Bridged Hybrid particles, with $100 \mathrm{mM}$ ammonium formate, $\mathrm{pH} 4.4$, as solvent $\mathrm{A}$ and acetonitrile as solvent B. Separation method used a linear gradient of $70 \%-53 \%$ acetonitrile $(\mathrm{v} / \mathrm{v})$ at a flow rate of $0.56 \mathrm{~mL} / \mathrm{min}$ in a 23-minute analytical run. Samples are maintained at $10^{\circ} \mathrm{C}$ before injection, and the separation temperature was $25^{\circ} \mathrm{C}$.

Sialic acid content was measured according to Warren. ${ }^{12}$ One milliliter of $20 \%$ trichloroacetic acid was added to samples of $50 \mu \mathrm{L}$ LDL containing 30-150 $\mu \mathrm{g}$ of protein, and the samples were incubated for 20 minutes at $4^{\circ} \mathrm{C}$ followed by centrifugation for 15 minutes at 4,500 rpm. Supernatant was discarded, and $250 \mu \mathrm{L}$ of $5 \%$ Trichloroacetic acid (TCA) was added, followed by a hydrolysis for 7 minutes at $100^{\circ} \mathrm{C}$. In order to eliminate possible influence of oxidized lipids on the reaction, oxidized lipids were extracted with $1 \mathrm{~mL}$ of chloroform for 30 minutes at room temperature, after which chloroform phase was discarded. Then, $250 \mu \mathrm{L}$ of $0.2 \%$ resorcin dissolved in $10 \mathrm{~N} \mathrm{HCl}$, containing $25 \mu \mathrm{M}$ of copper sulfate, was added to the residual water phase. The samples were incubated for 15 minutes at $100^{\circ} \mathrm{C}$, followed by extraction of the colored product by $600 \mu \mathrm{L}$ of butyl acetate:isobutanol $(85: 15 \mathrm{v} / \mathrm{v})$ mixture. The mixture was vigorously vortexed and then phase separation was put in spectrophotometer Yanaco (Houston Instruments, Houston, TX, USA) tuned to $630 \mathrm{~nm}$ wavelength in $1 \mathrm{~cm}$ quartz cuvette; $1 \mathrm{mg} / \mathrm{mL} N$-acetylneuraminic acid was used as a standard.

\section{Statistical analysis}

The results were analyzed using one-way analysis of variance. Statistical analysis was performed using IBM SPSS 21.0 software (IBM Corporation, Armonk, NY, USA). The data are presented in terms of mean and standard deviation. The significance of differences was defined at the 0.05 level of confidence.

\section{Results}

The comparison of baseline data between healthy subjects, individuals with asymptomatic carotid atherosclerosis, and patients with coronary atherosclerosis revealed no significant differences between study groups in body mass index values, systolic and diastolic blood pressure, smoking, family history of coronary heart disease/hypertension/type 2 diabetes, total cholesterol, triglycerides, high-density lipoprotein-, and LDL cholesterol (Table 1). The only exception was the age, which was significantly higher in patients with coronary atherosclerosis as compared to either healthy subjects or individuals with asymptomatic carotid atherosclerosis.

Protein-conjugated monosaccharide content was analyzed in LDL samples obtained from ten healthy subjects, ten 
patients with coronary atherosclerotic, and ten individuals with asymptomatic carotid atherosclerosis. In samples from healthy subjects, protein and apoB glycoconjugate composition included $N$-acetyl-glucosamine, galactose, mannose, and sialic acid in a molar ratio of 2:1:2.5:1 (Tables 2 and 3). Protein and apoB fractions of LDL from atherosclerotic patients contained similar amounts of glucosamine, galactose, and mannose, but lower level of sialic acid as compared to healthy subjects.

Carbohydrate composition of lipid fraction of LDL was characterized by the absence of mannose and the presence of $\mathrm{N}$-acetylgalactosamine and glucose, lower amount of $\mathrm{N}$-acetylglucosamine, and increased amount of galactose in comparison to apoB glycoconjugates (Table 4). Lipid fraction also contained less sialic acid. Some samples also contained traces of fucose (not presented). Lipid-bound glycoconjugates of total LDL from patients with coronary and carotid atherosclerosis contained less neutral monosaccharides than total LDL from healthy subjects. Patient-derived LDL also contained significantly less sialic acid (Table 4).

In samples from healthy subjects, total level of lipidbound monosaccharides in cmLDL was 1.5-2-fold lower than in native LDL. In samples from atherosclerotic patients, both neutral carbohydrates and sialic acid contents of cmLDL were decreased by 1.5-2-fold in comparison to native LDL, and total level of carbohydrates was lower than that measured in cmLDL of healthy subjects (Table 5). Sialic acid content of cmLDL from healthy donors was lower than that of native LDL (Table 5).

\section{Discussion}

In this work, we have compared the carbohydrate composition of LDL extracted from the blood of healthy subjects, patients with asymptomatic carotid atherosclerosis, and patients with coronary atherosclerosis. We have previously shown that LDL from atherosclerotic patients contains less sialic acid and confirmed, therefore, our earlier observations. $^{2}$ We have developed a method based on affine chromatography to extract desialylated LDL from total LDL fraction. ${ }^{2}$ This method was used in the current work to compare the carbohydrate composition of desialylated and normally sialylated LDL. A similar study has been performed earlier. ${ }^{13}$ However, in the present study, we used a different method to measure the carbohydrate content and included a group of subjects with asymptomatic carotid atherosclerosis. Moreover, the study groups were larger.

Table 2 Carbohydrate content of protein conjugates of total LDL of healthy individuals and patients with atherosclerosis

\begin{tabular}{|c|c|c|c|c|}
\hline \multicolumn{5}{|c|}{ Carbohydrate content, $\mathrm{nmol} / \mathrm{mg}$ of protein } \\
\hline Category & N-Acetylglucosamine & Galactose & Mannose & Sialic acid \\
\hline \multicolumn{5}{|c|}{ Healthy individuals } \\
\hline Mean & $59.3 \pm 4.8$ & $28.4 \pm 2.7$ & $74.0 \pm 5.8$ & $29.5 \pm 2.8$ \\
\hline \multicolumn{5}{|c|}{ Patients with coronary atherosclerosis } \\
\hline Average & $56.9 \pm 3.3$ & $27.5 \pm 4.1$ & $73.3 \pm 9.1$ & $17.4^{\mathrm{a}} \pm 3.2$ \\
\hline$P$-value & 0.20 & 0.58 & 0.85 & $4.1 \times 10^{-8}$ \\
\hline \multicolumn{5}{|c|}{ Patients with carotid atherosclerosis } \\
\hline Mean & $57.2 \pm 4.0$ & $27.3 \pm 5.5$ & $74.2 \pm 9.0$ & $19.6^{\mathrm{a}} \pm 5.8$ \\
\hline$P$-value & 0.29 & 0.58 & 0.94 & $3 \times 10^{-4}$ \\
\hline
\end{tabular}

Notes: Mean of ten independent measurements \pm SD is presented. aSignificant difference from the healthy individuals.

Abbreviations: LDL, low-density lipoprotein; SD, standard deviation.

Table 3 Carbohydrate conjugates composition of apoB protein from native LDL and circulating modified LDL in healthy individuals and atherosclerotic patients

\begin{tabular}{|c|c|c|c|c|}
\hline \multicolumn{5}{|c|}{ Carbohydrate content, nmol/mg of protein } \\
\hline Category & N-Acetylglucosamine & Galactose & Mannose & Sialic acid \\
\hline \multicolumn{5}{|c|}{ Healthy individuals } \\
\hline Mean & $57.6 \pm 5.8$ & $27.4 \pm 4.3$ & $73.7 \pm 5.8$ & $27.7 \pm 4.5$ \\
\hline \multicolumn{5}{|c|}{ Patients with coronary atherosclerosis } \\
\hline Mean & $59.1 \pm 5.8$ & $29.2 \pm 5.6$ & $73.7 \pm 9.1$ & $16.7^{\mathrm{a}} \pm 3.8$ \\
\hline$P$-value & 0.56 & 0.42 & 0.99 & $7.8 \times 10^{-6}$ \\
\hline \multicolumn{5}{|c|}{ Patients with carotid atherosclerosis } \\
\hline Mean & $59.7 \pm 5.7$ & $28.3 \pm 5.4$ & $73 \pm 9.7$ & $19.8^{\mathrm{a}} \pm 2.6$ \\
\hline$P$-value & 0.43 & 0.68 & 0.86 & $13.4 \times 10^{-5}$ \\
\hline
\end{tabular}

Notes: Mean of ten independent measurements \pm SD is presented. aSignificant difference from the healthy individuals.

Abbreviations: LDL, low-density lipoprotein; SD, standard deviation. 
Table 4 Carbohydrate content of glycolipids of total LDL extracted from the blood of healthy individuals and atherosclerosis patients

\begin{tabular}{|c|c|c|c|c|c|}
\hline \multicolumn{6}{|c|}{ Carbohydrate content, $\mathrm{nM} / \mathrm{mg}$ of protein } \\
\hline & $\mathrm{N}$-Acetyl galactosamine & N-Acetyl glucosamine & Galactose & Glucose & Sialic acid \\
\hline \multicolumn{6}{|c|}{ Healthy donors } \\
\hline Mean & $6.5 \pm 1.4$ & $8.9 \pm 1.8$ & $44.4 \pm 8.4$ & $48.7 \pm 8.7$ & $7.9 \pm 1.1$ \\
\hline \multicolumn{6}{|c|}{ Patients with coronary atherosclerosis } \\
\hline Mean & $2.4^{\mathrm{a}} \pm 0.5$ & $4.1 \pm \pm 1.7$ & $27.3^{a} \pm 5.2$ & $28.8^{\mathrm{a}} \pm 6.2$ & $3.6^{\mathrm{a}} \pm 1.5$ \\
\hline$P$-value & $1.7 \times 10^{-6}$ & $5.7 \times 10^{-6}$ & $6.5 \times 10^{-5}$ & $2 \times 10^{-5}$ & $1.1 \times 10^{-6}$ \\
\hline \multicolumn{6}{|c|}{ Patients with carotid atherosclerosis } \\
\hline Mean & $3.5^{\mathrm{a}} \pm 0.8$ & $5.5^{\mathrm{a}} \pm 1.4$ & $36 * * \pm 3.4$ & $37.9^{a} \pm 5.2$ & $4.8^{\mathrm{a}} \pm 1$ \\
\hline$P$-value & $2.6 \times 10^{-5}$ & $1.3 \times 10^{-4}$ & 0.0125 & $4.1 \times 10^{-3}$ & $4.5 \times 10^{-6}$ \\
\hline
\end{tabular}

Notes: Mean of ten independent measurements \pm SD is presented. aSignificant difference from the healthy individuals. Significant differences from healthy individuals are denoted by asterisk $*(P<0.00 \mathrm{I})$, or double asterisk $* *(P<0.05)$.

Abbreviations: LDL, low-density lipoprotein; SD, standard deviation.

Table 5 Carbohydrate conjugates composition of glycolipids from native LDL and circulating modified LDL in healthy individuals and atherosclerotic patients

\begin{tabular}{|c|c|c|c|c|c|}
\hline \multicolumn{6}{|c|}{ Carbohydrate content, nmol/mg of protein } \\
\hline & N-Acetylgalactosamine & $\mathrm{N}$-acetylglucosamine & Galactose & Glucose & Sialic acid \\
\hline \multicolumn{6}{|c|}{ Healthy individuals } \\
\hline \multicolumn{6}{|c|}{ Native LDL } \\
\hline Mean & $6.2 \pm 0.6$ & $8.8 \pm 0.8$ & $4 I \pm 5.9$ & $46 \pm 6.3$ & $7.1 \pm 0.7$ \\
\hline \multicolumn{6}{|l|}{$\mathrm{cmLDL}$} \\
\hline Mean & $3.8 \pm 0.7$ & $6.2^{\mathrm{a}} \pm 0.9$ & $28.3^{a} \pm 3.8$ & $29.4^{\mathrm{a}} \pm 6$ & $3.3^{\mathrm{a}} \pm 0.4$ \\
\hline$P$-value & $1.4 \times 10^{-7}$ & $2.1 \times 10^{-6}$ & $3.3 \times 10^{-5}$ & $1.1 \times 10^{-5}$ & $7.2 \times 10^{-10}$ \\
\hline \multicolumn{6}{|c|}{ Patients with coronary atherosclerosis } \\
\hline \multicolumn{6}{|c|}{ Native LDL } \\
\hline Mean & $3.8 \pm 0.8$ & $4.7 \pm 1.4$ & $34.7 \pm 3.4$ & $40.8 \pm 4.3$ & $5.3 \pm 1.6$ \\
\hline \multicolumn{6}{|l|}{$\mathrm{cmLDL}$} \\
\hline Mean & $1.4^{\mathrm{a}} \pm 0.4$ & $1.6^{\mathrm{a}} \pm 0.6$ & $17.3^{\mathrm{a}} \pm 2.8$ & $33.2 \pm 48.4$ & $1.6^{\mathrm{a}} \pm 0.8$ \\
\hline$P$-value & $1.2 \times 10^{-6}$ & $4.4 \times 10^{-5}$ & $4.7 \times 10^{-10}$ & 0.63 & $2.4 \times 10^{-5}$ \\
\hline \multicolumn{6}{|c|}{ Patients with carotid atherosclerosis } \\
\hline \multicolumn{6}{|c|}{ Native LDL } \\
\hline Mean & $4.2 \pm 0.9$ & $4.8 \pm 1$ & $35.1 \pm 2.4$ & $39.4 \pm 6.2$ & $5.8 \pm 1.4$ \\
\hline \multicolumn{6}{|l|}{$\mathrm{cmLDL}$} \\
\hline Mean & $2.4^{\mathrm{a}} \pm 0.3$ & $2.5^{\mathrm{a}} \pm 0.7$ & $22 . \mathrm{I}^{\mathrm{a}} \pm 4.4$ & $20.9^{\mathrm{a}} \pm 4$ & $2.6^{\mathrm{a}} \pm 1$ \\
\hline$P$-value & $1.1 \times 10^{-4}$ & $1.6 \times 10^{-5}$ & $1.1 \times 10^{-6}$ & $8.5 \times 10^{-7}$ & $1.9 \times 10^{-5}$ \\
\hline
\end{tabular}

Notes: Mean of ten independent measurements \pm standard deviation is presented. asignificant differences of $\mathrm{cmLDL}$ from native LDL.

Abbreviations: $\mathrm{cmLDL}$, circulating modified LDL; LDL, low-density lipoprotein.

Importantly, the obtained results were in accordance with those reported previously.

Carbohydrate composition of protein glycoconjugates from total LDL preparations has been studied by a number of authors. Total level of carbohydrates varied from $30 \mu \mathrm{g} / \mathrm{mg}$ to $130 \mu \mathrm{g} / \mathrm{mg}$ of protein. ${ }^{14-20}$ In our study, total monosaccharide content was $35-45 \mu \mathrm{g} / \mathrm{mg}$ of protein. The ratio of $\mathrm{N}$-acetyl-glucosamine, galactose, mannose, and sialic acid was $2: 1: 2.5: 1$, which was in accordance with previously published data. ${ }^{14-20}$

There are two types of protein glycoconjugates in LDL: biantennary sialylated (acidic) chains and high-mannose chains. ${ }^{6,17-21}$ As suggested by Taniguchi et al, ${ }^{6}$ apolipoproteinB molecule contains five to six high-mannose and eight to ten biantennary sialylated conjugates. It can therefore be proposed that carbohydrate composition of protein glycoconjugates should be approximately the following: $N$-acetyl glucosamine, 42-52 (mol/mol apo-B); galactose, $14-18 \mathrm{~mol} / \mathrm{mol}$ ApoB; mannose, 60-73 mol/mol ApoB; and sialic acid, $12-15 \mathrm{~mol} / \mathrm{mol}$ ApoB. According to our data, the content of galactose and sialic acid in apo-B of healthy subjects was $14 \mathrm{~mol} / \mathrm{mol}$ and $15 \mathrm{~mol} / \mathrm{mol}$ apo-B, respectively. This is in accordance with previously published observations. ${ }^{22}$ On the other hand, the contents of $\mathrm{N}$-acetyl glucosamine and mannose were $30 \mathrm{~mol} / \mathrm{mol}$ and $38 \mathrm{~mol} / \mathrm{mol}$ apo-B, respectively, which was 1.5 -fold lower than that reported by the cited authors. Other authors have also reported lower contents of $\mathrm{N}$-acetyl glucosamine and mannose in comparison with the 
expected levels. ${ }^{16,17}$ In their calculations, Taniguchi et $\mathrm{al}^{22}$ were based on the expectation that 13-16 of asparagine residues in apo-B are glycosylated. The available data support the suggestion that not all these asparagine residues are glycosylated. Moreover, LDL can contain a lower amount of high-mannose chains. This hypothesis, however, remains to be proven experimentally.

Lipid-conjugated glycoconjugates of human LDL include $N$-acetyl galactosamine and glucosamine, galactose, glucose, and sialic acid. The amounts of each individual monosaccharide in the lipid fraction of total LDL preparation were decreased in samples from atherosclerosis patients in comparison with those obtained from healthy subjects. The level of lipid-conjugated neutral carbohydrates was 1.5-2-fold lower in cmLDL in comparison to native LDL. The difference in sialic acid content was even more pronounced. Earlier studies reported the levels of sialic acid and total neutral carbohydrates in LDL from subjects with different LDL profiles. $^{23}$

It was demonstrated that small dense LDL contained less sialic acid and neutral carbohydrates. In our work, we separated total LDL into fractions with different sialic acid contents and demonstrated that desialylated LDL that also had decreased amounts of other carbohydrates was characterized by a smaller particle size and increased density in comparison to sialylated lipoproteins. ${ }^{2}$ Taken together, these observations demonstrate a link between lipoprotein particle size and density and carbohydrate content.

Although the exact mechanism of changes in the carbohydrate composition of LDL remains to be determined, it can be speculated that these changes affect lipoprotein metabolism. It has been demonstrated that varying sialic acid content altered the uptake and degradation of LDL by the smooth muscular cells of the arterial wall. ${ }^{24}$ Taniguchi et $\mathrm{al}^{22}$ demonstrated that desialylation of LDL by neuraminidase treatment enhanced its metabolism by murine macrophages. In our experiments, treatment of LDL with neuraminidase increased its uptake and lipid accumulation in cultured human aortic wall cells. ${ }^{2}$ Similar effects were described for cmLDL obtained from patients with atherosclerosis. Therefore, alterations of LDL carbohydrate composition, including desialylation, influence its ability to induce intracellular lipid accumulation. We have previously shown that intracellular lipid accumulation is a trigger of atherogenesis at the cellular level, which is followed by all the major signs of atherosclerosis. ${ }^{2}$ It can be suggested that deglycosylation is a key atherogenic modification of LDL.

\section{Conclusion}

We demonstrated altered composition of glycoconjugates in LDL isolated from the blood of atherosclerotic patients in comparison to healthy subjects. The most considerable change was the decrease in sialic acid content. Circulating modified LDL was characterized by a decreased content of lipid-bound neutral monosaccharides in healthy subjects and by a decreased content of both neutral monosaccharides and sialic acid in atherosclerotic patients. The observed changes should be further evaluated for their clinical relevance as another marker of atherosclerosis.

\section{Acknowledgment}

This study was supported by Ministry of Education and Sciences, Russia (Project \# RFMEFI61614X0010).

\section{Disclosure}

The authors report no conflicts of interest in this work.

\section{References}

1. Weber C, Noels H. Atherosclerosis: current pathogenesis and therapeutic options. Nat Med. 2011;17(11):1410-1422.

2. Orekhov AN, Ivanova EA, Bobryshev YV. Chapter 2: Naturally occurring multiple-modified low density lipoprotein. In: Ruiz M, editor. Blood Lipids and Lipoproteins. New York: Nova Science Publishers Inc; 2015:13-54.

3. Sorlie PD, Cooper L, Schreiner PJ, Rosamond W, Szklo M. Repeatability and validity of the Rose questionnaire for angina pectoris in the Atherosclerosis Risk in Communities Study. J Clin Epidemiol. 1996;49(7):719-725.

4. Graff-Iversen S, Selmer R, Løchen ML. Rose angina predicts 23-year coronary heart disease mortality in women and men aged $40-49$ years. Heart. 2008;94(4):482-486.

5. Tertov VV, Kaplun VV, Dvoryantsev SN, Orekhov AN. Apolipoprotein B-bound lipids as a marker for evaluation of low density lipoprotein oxidation in vivo. Biochem Biophys Res Commun. 1995;214(2): 608-613.

6. Taniguchi T, Ishikawa Y, Tsunemitsu M, Fukuzaki H. The structures of the asparagine-linked sugar chains of human apolipoprotein B-100. Arch Biochem Biophys. 1989;273(1):197-205.

7. Olsson U, Ostergren-Lundén G, Moses J. Glycosaminoglycan-lipoprotein interaction. Glycoconj J. 2001;18(10):789-797.

8. Wu AM, Song SC, Sugii S, Herp A. Differential binding properties of $\mathrm{Gal} / \mathrm{GalNAc}$ specific lectins available for characterization of glycoreceptors. Indian J Biochem Biophys. 1997;34(1-2):61-71.

9. Xu X, Ashline D, Liu L, et al. The glycosylation-dependent interaction of perlecan core protein with LDL: implications for atherosclerosis. J Lipid Res. 2015;56(2):266-276.

10. Axen R, Porath J. Chemical coupling of enzymes to cross-linked dextran ('Sephadex'). Nature. 1966;210(5034):367-369.

11. Sobenin IA, Salonen JT, Zhelankin AV, et al. Low density lipoproteincontaining circulating immune complexes: role in atherosclerosis and diagnostic value. Biomed Res Int. 2014;2014:205697.

12. Warren L. The thiobarbituric acid assay of sialic acids. J Biol Chem. 1959;234(8):1971-1975. 
13. Tertov VV, Orekhov AN, Sobenin IA, Morrisett JD, Gotto AM Jr, Guevara JG Jr. Carbohydrate composition of protein and lipid components in sialic acid-rich and -poor low density lipoproteins from subjects with and with-out coronary artery disease. J Lipid Res. 1993;34(3): 365-375.

14. Lee P, Breckenridge WC. The carbohydrate composition of human apolipoprotein low density lipoprotein from normal and type II hyperlipoproteinemic subjects. Can J Biochem. 1976;54:42-49.

15. Fontaine M, Malmendier CL. Carbohydrate content of human VLDL, IDL, LDL and HDL plasma apolipoproteins from fasting normal and hyperlipemic patients. Clin Chim Acta. 1975;64(1):91-93.

16. Fontaine M, Malmendier CL. Relationship between the carbohydrate content of lipoproteins of VLDL, IDL and LDL and the plasma level of these lipoproteins in man. Atherosclerosis. 1978;30(4):285-292.

17. Swaminathan N, Aladjem P. The monosaccharide composition and sequence of the carbohydrate moiety of human serum low density lipoproteins. Biochemistry. 1976;19(7):1516-1522.

18. Schultze HE, Heide K. Carbohydrate content of different blood components. Med Grundlogenforsch. 1960;3:357.
19. Van Der Bijl P. Human serum low density lipoproteins: carbohydrate composition in health and disease. In: Protides of the Biological Fluids. Oxford: Pergamon Press; 1974:309-314.

20. Van der Bijl P, Reman PC. Human very low density lipoproteins: loss of electrophoretic mobility on enzymatic removal of sialic acid residues. Clin Chim Acta. 1975;60:191-195.

21. Vauhkonen M, Viitala J, Parkkinen J, Rauvala H. High-mannose structure of apolipoprotein-B from low-density lipoproteins of human plasma. Eur J Biochem. 1985;152(1):43-50.

22. Taniguchi T, Ishikava $\mathrm{Y}$, Tsunemitsu M, Asaoka Y, Matsumoto K, Fukuzaki H. Stimulation of cholesteryl ester synthesis in human monocite-derived macrophages by asialo low density lipoproteins. Arteriosclerosis. 1989;9:767.

23. La Belle M, Krauss RM. Differences in carbohydrate content of low density lipoproteins associated with low density lipoprotein subclass patterns. J Lipid Res. 1990;31(9):1577-1588.

24. Filipovic I, Buddecke E. Desialized low-density lipoprotein regulates cholesterol metabolism in receptor-deficient fibroblasts. Eur J Biochem 1979;101(1):119-122.
Vascular Health and Risk Management

\section{Publish your work in this journal}

Vascular Health and Risk Management is an international, peerreviewed journal of therapeutics and risk management, focusing on concise rapid reporting of clinical studies on the processes involved in the maintenance of vascular health; the monitoring, prevention and treatment of vascular disease and its sequelae; and the involvement of

\section{Dovepress}

metabolic disorders, particularly diabetes. This journal is indexed on PubMed Central and MedLine. The manuscript management system is completely online and includes a very quick and fair peer-review system, which is all easy to use. Visit http://www.dovepress.com/ testimonials.php to read real quotes from published authors. 